\title{
A importância da vigilância epidemiológica no combate à Doença de Chagas: uma revisão integrativa
}

\author{
The importance of epidemiological surveillance in combating Chagas Disease:an \\ integrative review \\ La importancia de la vigilancia epidemiológica en la lucha contra la Enfermedad de \\ Chagas: una revisión integrativa
}

Leonardo Fernandes Geres ${ }^{1 *}$, Larissa Teodoro Rabi ${ }^{1}$, Taís Rondello Bonatti ${ }^{1}$.

\begin{abstract}
RESUMO
Objetivo: Revisar trabalhos originais com abrangência nacional de amostragem epidemiológica com o intuito de discutir o perfil epidemiológico da Doença de Chagas (DC) pelo país ao longo dos anos, relacionar a epidemiologia com o controle da doença e abordar as necessidades e lacunas dos estudos epidemiológicos. Métodos: Trata-se de um artigo de revisão integrativa, com busca de artigos originais de 2016 a 2021 nas bases de dados Scielo, Pubmed, Lilacs e se utilizou os descritores "Doença de Chagas", "Chagas Disease", "Incidence Chagas disease" e "Mortality Chagas disease". Resultados: Foram identificados 128 artigos para a leitura de título e abstract, apenas 42 foram selecionados e lidos integralmente e foram selecionados 16 artigos originais que se enquadravam dentro da metodologia de busca para esta revisão integrativa. Observou-se que a maior parte dos estudos atuais utilizam técnicas analíticas e geoprocessamento a partir de dados secundários como o Sistema de Informação de Agravos e Notificações (SINAN). Também foi observado que o país tem um fraco sistema de vigilância epidemiológica. Considerações finais: As pesquisas deste artigo de revisão integrativa apontam a necessidade de trabalhos com amostragem epidemiológica em nível nacional, devido aos poucos trabalhos originais encontrados.
\end{abstract}

Palavras-chave: Doença de Chagas, Epidemiologia, Incidência, Mortalidade.

\begin{abstract}
Objective: To review original works with national coverage of epidemiological sampling in order to discuss the epidemiological profile of Chagas Disease across the country over the years, to relate epidemiology with disease control and address the needs and gap of epidemiological studies. Methods: This is an integrative review article, searching for original articles from 2016 to 2021 in the Scielo, Pubmed, Lilacs databases, using the descriptors "Doença de Chagas", "Chagas Disease", "Incidence Chagas disease" e "Mortality Chagas disease" Results: 128 articles were identified for title and abstract reading, only 42 were selected and read in full and 16 original articles were selected that fit within the search methodology for this integrative review. It was observed that most of the current studies use analytical techniques and geoprocessing from secondary data such as the Information System for Diseases and Notifications (SINAN). It was also noted that the country has a weak epidemiological surveillance system. Final considerations: The research in this integrative review article indicate the need for studies with epidemiological sampling at a national level, due to the few original works found.
\end{abstract}

Key words: Chagas disease, Epidemiology, Incidence, Mortality.

\section{RESUMEN}

Objetivo: Revisar trabajos originales con cobertura nacional de muestreo epidemiológico con el fin de acercar el perfil epidemiológico de la Enf ermedad de Chagas en todo el país a lo largo de los años, relacionar la epidemiología con el control de la enf ermedad y abordar las necesidades y las lacunas de los estudios epidemiológicos. Métodos: Se trata de un artículo de revisión integradora, buscando artículos originales de 2016 a 2021 en las bases de datos Scielo, Pubmed, Lilacs, utilizando los descriptores "Doença de Chagas", "Chagas Disease", "Incidence Chagas disease" e "Mortality Chagas disease" Resultados: Se identificaron 128 artículos para lectura de título y resumen, solo 42 fueron seleccionados y leídos en su totalidad y se seleccionaron 16 artículos originales que encajan dentro de la metodología de búsqueda para esta revisión integradora. Se observó que la mayoría de los estudios actuales utilizan técnicas de análisis y geoprocesamiento a partir de datos secundarios como el Sistema de Información de Enfermedades y Notificaciones (SINAN). También se señaló que el país tiene un sistema de vigilancia

1 Universidade Paulista (UNIP), Campinas - SP. *E-mail: leo.serfg@hotmail.com

SUBMETIDO EM: 12/2021

ACEITO EM: 12/2021

PUBLICADO EM: 1/2022

REAS | Vol. 15 (1) | DOI: https://doi.org/10.25248/REAS.e9492.2022 
epidemiológica débil. Consideraciones finales: Las investigaciones de este artículo de revisión integradora señalan la necesidad de estudios con muestreo epidemiológico a nivel nacional, debido a los pocos trabajos originales encontrados.

Palabras clave: Enfermedad de Chagas, Epidemiología, Incidencia, Mortalidad.

\section{INTRODUÇÃO}

O Trypanosoma cruzi está presente na Terra desde os tempos remotos, com origem há milhares de anos quando os continentes ainda estavam unidos, circulando pelo tubo digestivo de espécies (aquáticas, répteis, entre outros). Com o passar do tempo, o parasito se adaptou e desenv olveu seu ciclo nos insetos hemípteros hematófagos e aos mamíferos de pequeno porte. Por início o tripanosoma teve seu ciclo estabelecido entres os insetos vetores e os marsupiais, entretanto, seu ciclo se estendeu para um segundo grupo, os primatas. A tripanossomíase, com o tempo, se concentrou e se distribuiu por toda América, estabelecendo pelo ciclo humano doméstico muito mais tarde (DIAS JCP, et al., 2016; PRATA A, et al, 2011; SANGENIS LHC, et al, 2016).

O Trypanosoma é o agente etiológico da Doença de Chagas, um protozoário de grande importância pública na América Latina, devido a incidência de notificações compulsórias e sua relação com as condições de vida inadequada e ao baixo nível socioeconômico. É uma doença parasitária tropical destacada pela Organização Mundial da Saúde (OMS) como uma importante enfermidade negligenciada (ACOSTA RODRÍGUEZ EV, et al., 2019; CORREIA JR, et al., 2021).

Sua patogenia envolve o alojamento do parasito em tecidos, podendo incluir na pele, Chagoma de Inoculação que são erupções cutânea ligeiramente salientes e duras, edema bipapebral (sinal de Romanã), insuficiência cardíaca (miocardite aguda difusa) e a Síndrome dos Megas que se desenvolvem como resultado da destruição irreversível dos plexos nervosos, nas vísceras ocas, a destruição de células ganglionares provoca, com o passar do tempo, o aparecimento das dilatações, hipertrofias e formação de granulomas (DIAS JCP, et al., 2011; PRATA A, et al., 2011).

$\mathrm{O}$ combate à Doença de Chagas enfrenta diversos problemas relacionados com o seu complexo sistema de transmissão que envolve vetores, transmissão oral, transmissão congênita e transfusão sanguínea que contribuem para a difusão desta protozoose (SANTOS E e FALCÃO LM, 2020). Atualmente no Brasil a principal via de transmissão é a oral, em consequência da ingestão de alimentos macerados junto com o vetor Triatoma infestans conhecido popularmente como barbeiro (PINHEIRO E, et al., 2017).

A vigilância epidemiológica funciona como uma importante ferramenta de contenção para a Doença de Chagas, porque se trata de uma zoonose que ainda não apresenta tratamento eficaz e específico. Atualmente os únicos medicamentos disponíveis para o tratamento são o nifurtimox e o benznidazol, medicamentos estes que são pouco eficazes contra o estágio crônico da DC, portanto a epidemiologia se torna essencial para traçar medidas profiláticas e também auxiliar na detecção de pacientes antes de atingirem o estágio crônico e iniciarem o tratamento ainda no estágio agudo aumentando a possibilidade de êxitos no tratamento (LIDANI KC, et al., 2019; FONSECA BP, et al., 2020).

Dessa forma o objetivo do trabalho foi realçar a capacidade da vigilância epidemiológica como forma de contenção da doença e trazer um panorama epidemiológico da doença pelo país ao longo dos anos através da análise de artigos, assim como também avaliar as pesquisas epidemiológicas originais recentes, discutindo os dados das pesquisas atuais, trazendo futuras perspectivas e necessidades.

\section{MÉTODOS}

Trata-se de um artigo de revisão integrativa, foram utilizados artigos científicos coletados nas bases de dados Scientific Electronic Library online (Scielo), PubMed, Medical Literature Analysis and Retrieval System Online (Medline), Literatura Latino-Americana e do caribe em ciências da saúde (Lilacs), Google Acadêmico e Portal de Periódico Capes, por meio da busca de palavras chaves como "Epidemiologia no combate a Chagas", "Vigilância epidemiológica no combate a Chagas", "inquérito de dados Chagas", "Transmissão da 
doença de Chagas", "Trypanossoma cruzi", "Doença de Chagas ", "Chagas Disease", "Incidence Chagas disease" "Mortality Chagas disease" e "Epidemiology".

Os critérios de inclusão foram artigos originais com data de publicação de 2016 a 2021, artigos publicados em português ou inglês, artigos de vigilância epidemiológica com amostragem ou relevância a nível nacional e foram selecionados os artigos científicos originais mais relevantes em relação a vigilância epidemiológica no combate à Doença de Chagas que se enquadrassem no tema. Assim como, os critérios de exclusão foram artigos com datas de publicação fora das datas estipuladas, artigos em línguas não estipuladas, e artigos de vigilância epidemiológica de abrangência regional.

\section{RESULTADOS E DISCUSSÃO}

Foram encontrados inicialmente 128 artigos originais nas bases de dado Pubmed, Lilacs, Medline, Scielo, Google Acadêmico e Portal Periódico Capes. Após a seleção e busca inicial foi realizada a leitura do título e abstract de todos os artigos selecionados. Em seguida foram selecionados 42 artigos para leitura integral e, ao final, selecionados 16 artigos que se encaixavam no tema proposto e nos critérios de inclusão que incluía principalmente artigos de vigilância epidemiológica com amostragem Nacional e excluindo trabalhos que utilizaram amostragem regional. Somente um artigo com amostragem regional foi selecionado por trazer uma discussão a nível nacional. Por fim os 16 artigos foram utilizados para a elaboração desta revisão integrativa. A metodologia e processo de seleção dos artigos é exposto na Figura 1.

Figura 1 - Fluxograma do processo de seleção dos artigos da revisão integrativa.

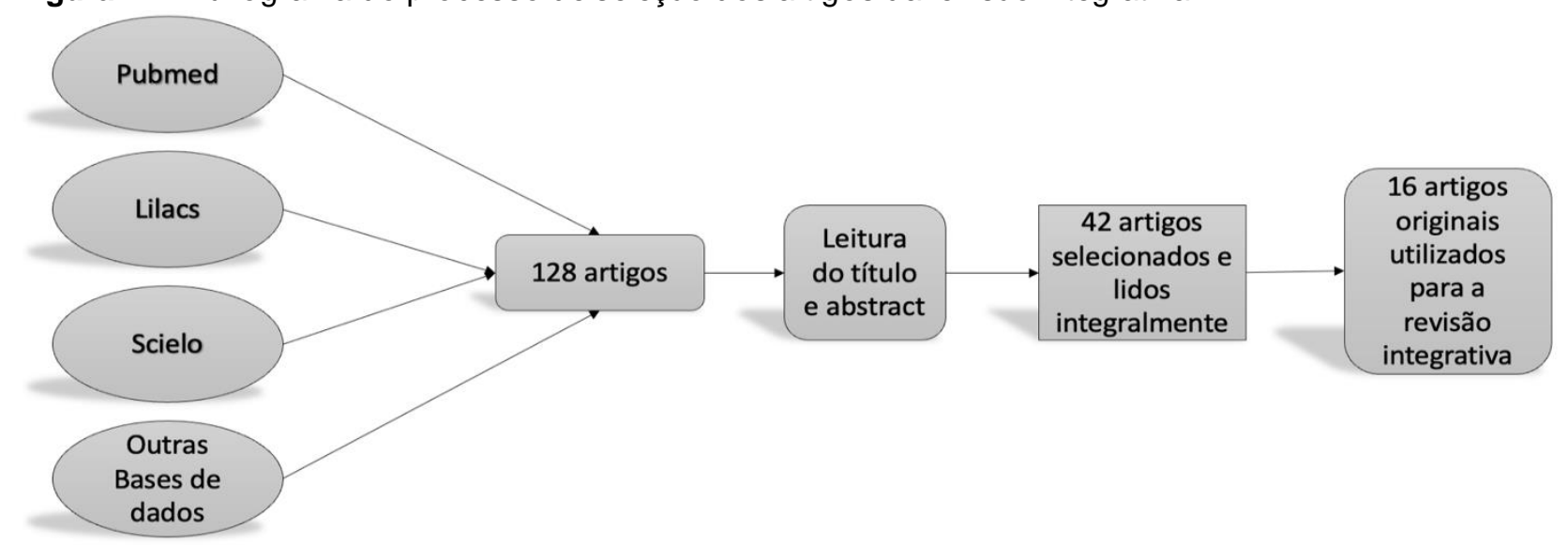

Fonte: Geres LF, et al., 2021.

Dos 16 artigos encontrados nesta revisão integrativa 9 artigos abordam pesquisas originais, sobre prevalência, incidência, mortalidade e aspectos sociais relacionados com a DC; 4 artigos estudam os métodos de coletânea de dados e diagnóstico para DC; 2 artigos avaliam a distribuição da DC no Brasil; um artigo analisa o conhecimento de profissionais da saúde sobre DC e as possibilidades de migrações da DC. A maior parte dos artigos analisados realizaram suas pesquisas a partir de dados secundários como o Sistema de Informações sobre Mortalidade (SIM) e Sistema de Informação de Agravos Notificáveis, dos casos notificados. Os artigos foram lidos na íntegra revisados, classificados conforme a sua descrição e apresentados no (Quadro 1).

Estudos de paleoparasitologia mostraram que a Doença de Chagas é uma enfermidade muito antiga no continente americano. As descobertas mais antigas, foram feitas em múmias do povo chinchorro, que viveram cerca de 9000 anos atrás, região onde hoje estão o sul do Peru e a cidade chilena de Antofagasta (Deserto do Atacama), por meio de técnicas de Reação em Cadeia da Polimerase (PCR) (Polymerase Chain Reaction) foi identificada a presença de Ácido Desoxirribonucleico (DNA) de T. cruzi. Outros estudos evidenciaram a existência da doença de Chagas em múmias do Chile e Peru de 4.000 anos atrás, anteriores ao surgimento da civilização Inca. (DIAS JCP, et al., 2011; PRATA A, et al., 2011; SANGENIS LHC, et al., 2016). 
Quadro 1 - Aspectos gerais dos estudos revisados

\begin{tabular}{|c|c|c|}
\hline Artigo, ano & Proposta & Principais achados \\
\hline Alencar ME, et al., 2021 & $\begin{array}{l}\text { Apresentar o comportamento epidemiológico da } \\
\text { Doença de Chagas aguda durante o período de } \\
\qquad 2001 \text { a } 2018 \text {. }\end{array}$ & $\begin{array}{l}\text { Os resultados apontaram que as maiores taxas de incidência ocorreram na região } \\
\text { norte do Brasil. A principal via de transmissão atual é a via oral. O grupo mais } \\
\text { acometido pela Doença são homens pardos acima de } 30 \text { anos, com baixo nível de } \\
\text { escolaridade das áreas rurais. }\end{array}$ \\
\hline Santos EF, et al., 2020 & $\begin{array}{l}\text { Identificar o perfil epidemiológico da Doença de } \\
\text { Chagas no Brasil entre } 2001 \text { e } 2018 \text {. }\end{array}$ & $\begin{array}{l}\text { Os achados apontaram um rápido aumento da Doença de Chagas próximo a } 2005 \text {, } \\
\text { uma queda estável de } 2005 \text { a } 2009 \text {, seguido por um aumento na taxa de incidência } \\
\text { após o ano de } 2009 \text {. }\end{array}$ \\
\hline Simões TC, et al., 2018 & $\begin{array}{l}\text { Analisar a evolução da mortalidade da Doença } \\
\text { de Chagas no Brasil entre } 1980 \text { e } 2014 \text {. }\end{array}$ & $\begin{array}{l}\text { Os resultados são equivalentes à dados de outros autores, o perfil epidemiológico } \\
\text { da doença acomete principalmente homens acima de } 30 \text { anos com baixo nível de } \\
\text { escolaridade. }\end{array}$ \\
\hline $\begin{array}{l}\text { Gonçalves W, et al., } \\
\qquad 2021\end{array}$ & $\begin{array}{l}\text { Verificar e analisar a mortalidade de pacientes } \\
\text { com Doença de Chagas entre } 2010 \text { e } 2019 .\end{array}$ & $\begin{array}{c}\text { Os dados apresentados se relacionam com outras pesquisas, mostrando que o } \\
\text { norte do Brasil é uma região endêmica, o sexo masculino, pessoas com menor } \\
\text { escolaridade e economicamente ativos são mais acometidos. }\end{array}$ \\
\hline Brandão E, et al., 2017 & $\begin{array}{l}\text { Analisar as Doenças Tropicais entre crianças e } \\
\text { adolescentes no período de } 2009 \text { a } 2013 .\end{array}$ & $\begin{array}{l}\text { Os resultados mostram que a Leishmaniose e a Doença de Chagas foram as } \\
\text { Doenças tropicais que apresentaram maior letalidade entre jovens e crianças. }\end{array}$ \\
\hline Xavier IGG, et al., 2021 & $\begin{array}{l}\text { Determinar a prevalência de pacientes } \\
\text { acometidos pela síndrome metabólica causada } \\
\text { pela Doença de Chagas. }\end{array}$ & $\begin{array}{c}\text { Embora a amostragem epidemiológica tenha selecionado somente pacientes da } \\
\text { cidade do Rio de janeiro, se trata de um estudo no qual a presença da doença de } \\
\text { chagas foi confirmada por teste imunológico e os resultados se comportaram } \\
\text { diferente de outros estudos Nacionais que realizaram suas análises através de } \\
\text { dados secundários do Departamento de informática do Sistema Único de Saúde } \\
\text { (DataSus). }\end{array}$ \\
\hline Souza HP, et al., 2020 & $\begin{array}{l}\text { Analisar áreas críticas de Doenças parasitárias, } \\
\text { associando com fatores sociais entre } 2010 \text { e } \\
2017 .\end{array}$ & $\begin{array}{l}\text { Os resultados mostram que quanto mais próximo de áreas sem saneamento } \\
\text { básico, maior a prevalência de doenças parasitárias, incluindo a Doença de } \\
\text { Chagas. }\end{array}$ \\
\hline $\begin{array}{l}\text { Martins Mello FR, et al., } \\
2018\end{array}$ & $\begin{array}{c}\text { Avaliar as Doenças Tropicais Negligenciadas no } \\
\text { Brasil entre } 1990 \text { e } 2016 .\end{array}$ & $\begin{array}{l}\text { Entre as doenças parasitárias negligenciadas a Doença de chagas é a Doença que } \\
\text { mais demora para apresentar problemas patológicos no paciente, permitindo assim } \\
\text { que o paciente tenha uma vida saudável por anos. }\end{array}$ \\
\hline Pessoni LL, et al., 2019 & $\begin{array}{l}\text { Analisar a prevalência da Doença de Chagas } \\
\text { entre doadores de sangue. }\end{array}$ & $\begin{array}{l}\text { Os resultados têm repercussão em nível nacional, mostrando que a Doença de } \\
\text { Chagas é muito prevalente no Brasil. }\end{array}$ \\
\hline Vergara C, et al., 2019 & $\begin{array}{l}\text { Determinar por Polymerase chain Reaction } \\
\text { (PCR) a presença de Tripanosoma cruzi em } \\
\text { pacientes adultos com Doença de Chagas já } \\
\text { confirmada e seis anos após tratamento com } \\
\text { nifurtimox }\end{array}$ & $\begin{array}{c}\text { Apesar de não se tratar de um estudo focado em uma metodologia para } \\
\text { epidemiologia, os resultados mostram a presença de falsos negativos, e a } \\
\text { necessidade de se pensar a coleta de dados epidemiológicos de maneira diferente. } \\
\text { Os dados apresentados mostram que a técnica de PCR é um método mais } \\
\text { específico para diagnóstico da DC. }\end{array}$ \\
\hline
\end{tabular}




\begin{tabular}{|c|c|c|}
\hline Artigo, ano & Proposta & Principais achados \\
\hline $\begin{array}{l}\text { Sáez-Alquezar A, et al., } \\
2021\end{array}$ & $\begin{array}{l}\text { Examinar kits de ensaios imunológicos e } \\
\text { amostras de sangue de pacientes já } \\
\text { determinados com Doença de Chagas de } \\
\text { diversas regiões do País. }\end{array}$ & $\begin{array}{c}\text { Os resultados mostram que os kits em geral demonstram resultados satisfatório, } \\
\text { porém os resultados mostraram variação em relação à alguns estados. Os dados } \\
\text { destes autores corroboram para a necessidade do treinamento de analistas } \\
\text { laboratoriais e de se escolher kits referências ou aprovados pela Agência Nacional } \\
\text { de vigilância Sanitária (ANVISA). }\end{array}$ \\
\hline $\begin{array}{l}\text { Ferreira-Silva MM, et } \\
\text { al., } 2020\end{array}$ & $\begin{array}{l}\text { Analisar a performance de kits de ensaios } \\
\text { imunológicos entre doadores de sangue. }\end{array}$ & $\begin{array}{c}\text { Teste ELISA apresentou maior especificidade em relação a outros testes. } \\
\text { Os resultados corroboram cada vez mais para a necessidade de se repensar a } \\
\text { maneira de analisar a positividade para Doença de Chagas entre doadores de } \\
\text { Sangue. }\end{array}$ \\
\hline Brossas JY, et al., 2021 & $\begin{array}{l}\text { Avaliar o teste de Western blotting para o } \\
\text { Diagnóstico da Doença de Chagas. }\end{array}$ & $\begin{array}{l}\text { Os resultados apresentam boas perspectivas iniciais, porém precisam ser melhor } \\
\text { elucidado em futuros trabalhos. Conclui-se que para as próximas décadas a coleta } \\
\text { de dados para amostragem epidemiológica precisam ser repensadas. }\end{array}$ \\
\hline Junior NC, et al., 2018 & $\begin{array}{c}\text { Analisar o conhecimento e a atuação de } \\
\text { profissionais do Sistema Único de Saúde (SUS) } \\
\text { frente as migrações bolivianas evidenciando a } \\
\text { Doença de Chagas. }\end{array}$ & $\begin{array}{l}\text { Os resultados demonstram a necessidade de revisar novas estratégias de controle } \\
\text { da Doença Chagas frente às migrações Bolivianas, visto o desconhecimento de } \\
\text { trabalhadores do SUS. }\end{array}$ \\
\hline $\begin{array}{l}\text { Anderson AE, et al., } \\
\qquad 2018\end{array}$ & $\begin{array}{l}\text { Avaliar a distribuição de vetores da Doença de } \\
\text { Chagas pelo território brasileiro. }\end{array}$ & $\begin{array}{l}\text { Os dados apresentam que a maior variedade de espécies vetores se encontram na } \\
\text { região nordeste, portanto apresentam maior possibilidade de infecção pela via } \\
\text { vetorial. }\end{array}$ \\
\hline $\begin{array}{l}\text { Gurgel-Goncalves R, et } \\
\text { al., } 2020\end{array}$ & $\begin{array}{l}\text { Apresentar o TriatoDex, aplicativo android } \\
\text { criado pelos autores para auxiliar na } \\
\text { identificação de Vetores da Doença de Chagas. }\end{array}$ & $\begin{array}{c}\text { O aplicativo pode contribuir para uma melhor elucidação da distribuição dos vetores } \\
\text { da Doença de Chagas, visto que com o aplicativo pessoas leigas também podem } \\
\text { analisar os vetores. }\end{array}$ \\
\hline
\end{tabular}

Fonte: Geres LF, et al., 2021. 
Alguns hábitos provenientes dos povos que tiveram contato com o Trypanosoma cruzi podem ter contribuído para a sua transmissão, como os povos chinchorro e Chacos, presentes na região da Argentina e do Paraguai que se alimentavam de carnes cruas. Outros povos como os andinos e os quéchuas no altiplano boliviano, desenvolveram a criação de Cavia aperea (conhecido popularmente como preá) que podem ter atraído a residência de triatomíneos para o ambiente populacional. Além disso, eram sociedades que tinham rituais religiosos, envolvendo o consumo de animais crus e sangue. (SANGENIS LHC, et al., 2016).

A teoria mais aceita dentre os pesquisadores indicam que o Triatoma infestans deve ter sido o principal responsável pela difusão em tantos países pela América Latina, no entanto alguns estudos mostram que por se tratar de populações primitivas que viviam a base de pesca e caças, elas tenham adquirido a Doença de Chagas por via oral, ao consumirem alimento de origem animal e silvestre. Por pouco se saber a respeito do inseto vetor (triatomíneos) em eras tão remotas, e sobre sua domiciliação, não é descartada a possibilidade de que a transmissão possa ter ocorrido tanto da forma vetorial, quanto da forma oral (SANGENIS LHC, et al., 2016).

Provavelmente a DC se expandiu e ganhou maior importância epidemiológica no Brasil, devido a colonização e a formação do Brasil império, quando o homem se aproximou do ambiente natural de vetores invertebrados (Triatoma infestans). No Sudeste, Nordeste e Centro Oeste do Brasil, indícios da doença humana só foram encontrados nos séculos XVIII e XIX (PRATA A, et al., 2011).

A Doença de Chagas só foi elucidada em 1909 pelo médico sanitarista Carlos Chagas que ao longo de sua viagem de caráter sanitarista, teve conhecimento de um percevejo hematófago, conhecido popularmente como barbeiro, que eram fortemente presentes na região. Chagas examinou alguns barbeiros e encontrou, em seu intestino, formas flageladas de um protozoário. Mais tarde ao examinar, Berenice, uma criança febril, encontrou finalmente o parasito em seu sangue, comprovando assim, a existência de uma nova doença humana ao mundo, com rumo diferente das pesquisas habituais de outras parasitoses naquele período (PRATA A et al., 2011; SANGENIS LHC, et al., 2016).

Em geral, as doenças eram primeiramente reconhecidas em pacientes que apresentavam patogenia ou em entidades mórbidas, e após o reconhecimento do agente etiológico, era traçado o ciclo do parasito. 0 estudo e discussão do ciclo de vida era investigado por anos, e a busca pelo vetor poderia demorar décadas. Pode-se citar como exemplo o trematódeo Schistosoma mansoni, para o qual todo o processo de descoberta durou 64 anos. No caso do protozoário Leishmania o processo durou 26 anos e, para a malária, 17 anos. 0 tripanosoma teve todo seu ciclo descoberto em apenas um ano (DIAS JCP, et al., 2011; SANGENIS LHC, et al., 2016; LIMA NT e BOTELHO A, et al., 2013; DIAS JCP, et al., 2016).

Em 1909, começaram a aparecer as primeiras informações clínicas, epidemiológicas e parasitológica, predominando descobertas relacionadas a enfermidade no estágio agudo, detectada basicamente por Carlos Chagas, mesmo com pouco conhecimento sobre a patogênese, já era possível entender a gravidade da doença pela larga disseminação do inseto vetor no continente americano. Dessa forma novas pesquisas foram iniciadas pela América, catalogando os primeiros casos da doença (DIAS JCP, et al., 2011; PRATA A, et al., 2011).

Em 1910 já se percebia a dificuldade em implementar e descobrir medicamentos eficazes ou até mesmo a criação de vacinas. Carlos Chagas já inferia que a difusão do inseto estava relacionada com a pobreza e as formas de moradia rural de péssima qualidade que atraíam o barbeiro e o serviam de moradia. Porém poucas medidas eficazes foram tomadas combatendo o inseto vetor ou pobreza nas regiões periféricas (DIAS JCP, et al., 2011; PRATA A, et al., 2011)

Somente em 1934, foi descrito o complexo of talmo ganglionar por Cecílio Romanã, e tal feito contribuiu para a descoberta de diversos casos pela América. Entre 1935 e 1945 a doença teve um maior reconhecimento continental de enfermidade e nas implicações do inseto vetor, tendo os primeiros ensaios ef etivos de combate ao vetor em Bambuí (MG). A linha do tempo dos principais acontecimentos relacionados com o controle da DC no Brasil é exposta na Figura 2 (DIAS JCP, et al., 2011; PRATA A, et al., 2011). 
Figura 2 - Linha do tempo dos principais acontecimentos relacionados com o controle da Doença de Chagas no Brasil.

\begin{tabular}{|c|c|c|c|c|c|c|c|}
\hline $\begin{array}{l}\text { A Doença de } \\
\text { Chagas é uma } \\
\text { enfermidade } \\
\text { muito antiga no } \\
\text { continente } \\
\text { americano. As } \\
\text { descobertas } \\
\text { mais antigas, } \\
\text { foram feitas em } \\
\text { múmias do } \\
\text { povo } \\
\text { chinchorro. }\end{array}$ & & $\begin{array}{l}\text { Foi descrito o } \\
\text { complexo } \\
\text { oftalmo } \\
\text { ganglionar por } \\
\text { Cecília Romanã, } \\
\text { e tal feito } \\
\text { contribuiu para a } \\
\text { descoberta de } \\
\text { diversos casos } \\
\text { pela América. }\end{array}$ & & $\begin{array}{l}\text { Inquérito de } 1975-1980 \text { foi } \\
\text { a primeira análise nacional } \\
\text { a ser realizada devido a } \\
\text { uma iniciativa de } \\
\text { campanhas de saúde } \\
\text { pública da extinta } \\
\text { Superintendência de } \\
\text { Campanhas de Saúde } \\
\text { Pública (SUCAM/MS) e do } \\
\text { Conselho Nacional de } \\
\text { Pesquisas (CNPq) através } \\
\text { de seu Programa Integrado } \\
\text { de Doenças Endêmicas } \\
\text { (PIDE). }\end{array}$ & & $\begin{array}{l}\text { Três mudanças } \\
\text { epidemiológicas } \\
\text { estatisticamente } \\
\text { significativas nas } \\
\text { tendências de tempo, } \\
\text { um rápido aumento por } \\
\text { volta de } 2005 \text { e } 2006, \\
\text { uma queda estável de } \\
2006 \text { a } 2009 \text {, seguida } \\
\text { por outra tendência de } \\
\text { aumento após } 2010 . \\
\text { Em } 2006 \text { o Brasil é } \\
\text { reconhecido pela } \\
\text { Organização } \\
\text { Pan-Americana como o } \\
\text { primeiro país a eliminar } \\
\text { o inseto vetor da } \\
\text { Doença de Chagas na } \\
\text { América Latina. }\end{array}$ & \\
\hline 6980 A.C & 1909 & 1934 & $1960-1970$ & $1975-1980$ & $1990-2000$ & 2001-2010 & 2010-2021 \\
\hline & $\begin{array}{l}\text { A Doença de } \\
\text { Chagas só foi } \\
\text { elucidada em } \\
1909 \text { pelo } \\
\text { médico } \\
\text { sanitarista } \\
\text { Carlos } \\
\text { Chagas, a } \\
\text { partir do } \\
\text { inseto vetor } \\
\text { em Lassance } \\
\text { (MG). } \\
\text { Chagas já } \\
\text { inferia que a } \\
\text { Doença } \\
\text { estava } \\
\text { relacionada } \\
\text { com a } \\
\text { pobreza. }\end{array}$ & & $\begin{array}{l}\text { Início tímido de } \\
\text { medidas } \\
\text { profiláticas e } \\
\text { estratégias } \\
\text { políticas contra a } \\
\text { Doença de } \\
\text { Chagas tomada } \\
\text { por diversos } \\
\text { países da } \\
\text { América Latina. }\end{array}$ & & $\begin{array}{l}\text { Progressiva eliminação } \\
\text { do vetor T.infestans e } \\
\text { redução nas taxas de } \\
\text { prevalencia da Doença de } \\
\text { Chagas. Por outro lado , } \\
\text { ocorreu a desativação de } \\
\text { diversos orgãos } \\
\text { responsáveis pela } \\
\text { vigilancia e controle da } \\
\text { Dença de Chagas, } \\
\text { descentralizando as } \\
\text { medidas para munícipios } \\
\text { e estados. }\end{array}$ & & $\begin{array}{l}\text { Elevação no número de } \\
\text { casos de Doença de } \\
\text { Chagas, dado ao } \\
\text { afrouxamento das medidas } \\
\text { políticas e epidemiológicas } \\
\text { no país. } \\
\text { Em } 2020 \text { a pandemia } \\
\text { covid-19 se estabelece no } \\
\text { Brasil. Os dados } \\
\text { epidemiológicos } \\
\text { apresentam uma queda na } \\
\text { taxa de incidência da } \\
\text { Doença de Chagas. }\end{array}$ \\
\hline
\end{tabular}

Nota: Imagem criada pelo Lucid.app. Fonte: Geres LF, et al., 2021. Baseado em: Dias JCP, et al., 2011; Prata A, et al., 2011. 
De certa forma, a falta de incentivo e pesquisas relacionadas a medidas profiláticas e tratamento, contribuíram para que as medidas de controle contra o inseto vetor com ampla sustentação só fossem ocorrer tardiamente por volta de 1970, devido as estratégias políticas, expansão das pesquisas, e os programas nacionais em diversos países da américa como o Brasil, Argentina, Uruguai, Chile, entre outros (ACOSTA RODRÍGUEZ EV, et al., 2019; DIAS JCP, et al., 2011).

Entre 1975 e 1980 foi realizado o primeiro inquérito nacional da DC devido a uma iniciativa de campanhas de saúde pública da extinta Superintendência de Campanhas de Saúde Pública (SUCAM/MS) e do Conselho Nacional de Pesquisas (CNPq) através de seu Programa Integrado de Doenças Endêmicas (PIDE). Assim foi possível analisar como um todo a epidemiologia da doença pelo país nas áreas rurais utilizando a mesma abordagem nos métodos de pesquisa (SILVEIRA AC et al., 2011).

Graças à análise de inquérito e abordagens mais específicas ao combate do vetor, o Brasil apresentou mudanças nas taxas de prevalência epidemiológica passando de uma prevalência de 4,2\% em 1980 para 0,96 em 1987. Essa decrescente da prevalência logo se estabilizou nos anos 90. Entretanto, devido aos poucos recursos financeiros dedicados ao controle da zoonose, a falta de testagem, migração rural até os polos urbanos, a falta de controle nos bancos de sangue, o desconhecimento e negligência da transmissão oral, o padrão epidemiológico mudou, fazendo com que a zoonose chegasse às áreas urbanas (SILVEIRA AC, et al.,2011; ALKMIN-OLIVEIRA SM, et al., 2014; HASHIMOTO K e YOSHIOKA K, 2012).

De acordo com diversos autores Santos EF, et al. (2020), Alencar MME, et al. (2021), Simões TC, et al. (2018) e Gonçalves W, et al. (2021) entre 2001 e 2020 pode-se dizer que ocorreu quatro mudanças significativas nas tendências de tempo, um rápido aumento por volta de 2005 e 2006, uma queda estável de 2006 a 2009, seguidapor outra tendência de aumento após 2010 e uma queda de incidência em 2020 durante a pandemia. Frequências mais altas foram observadas em homens e mulheres na região Norte. Além de se tratar de uma Doença prevalente, de acordo com o estudo de Pessoni LL, et al. (2019) a soroprevalência positiva entre doadores de sangue para $D C$ foi $0,21 \%$. Os casos diagnosticados de DC aguda por região e no Brasil entre 2001 e 2020 são mostrados no Gráfico 1.

Gráfico 1 - Casos diagnosticados de Doenças de Chagas aguda por Região e no Brasil, 2001-2020.

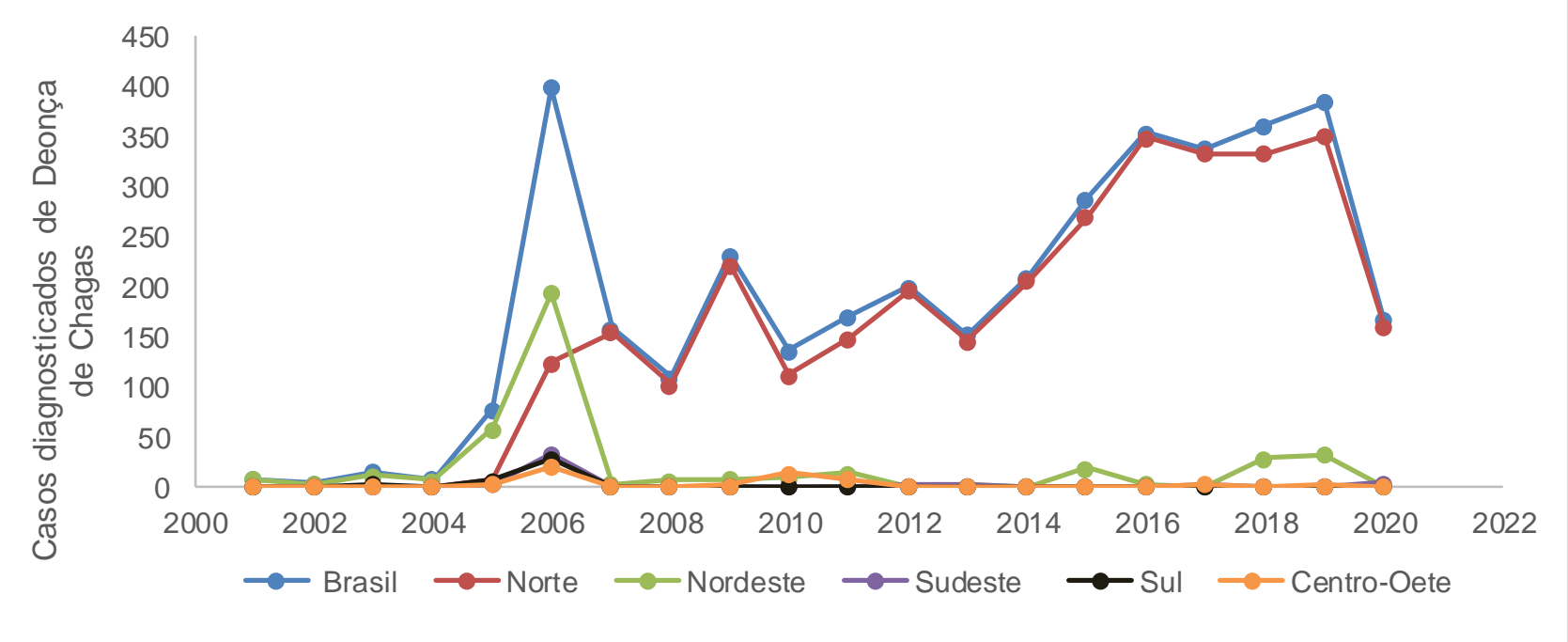

Fonte: Geres LF, et al., 2021.

A transmissão vetorial foi a principal rota relatada para região nordeste, enquanto a transmissão oral aumentou significativamente no Norte do país. A distribuição espaço-temporal foi heterogênea no Brasil ao longo do tempo e a DC se comportou mais prevalente em homens economicamente ativos, e na população parda (SANTOS EF, et al., 2020; ALENCAR MME, et al., 2021; GONÇALVES W, et al., 2021; MARTINS MELLO FR, et al., 2012). 
O perfil epidemiológico da DC pode se comportar de maneira inesperada e heterogênea já que estudo de Xavier IGG, et al. (2021) que calculou suas variáveis através de pacientes diagnosticados com exame imunológico na cidade do Rio de janeiro, trouxe um perfil epidemiológico com maior prevalência para o sexo feminino, desta forma por mais que este tenha sido um estudo com uma abordagem reduzida de amostragem, é realçado como pode ser heterogêneo o comportamento da DC, enquanto não ocorrer uma iniciativa pública na qual ocorra uma testagem e amostragem especifica dos pacientes em todo Brasil, os dados tenderão a ser imprecisos.

Martins mello FR, et al. (2018) em seus dados expõem que entre as doenças parasitárias a DC é a doença que proporciona mais anos de qualidade de vida ao paciente até que a patogenia se manifeste, mas epidemiologicamente essa característica contribui para a difusão da DC, pelo fato do paciente circular sem perceber a patogênese e não se tratar, podendo transmitir a doença a outros vetores e consequentemente à outras pessoas. Por mais que se trate de uma patogenia silenciosa, a DC é a doença parasitária que mais causa morte entre crianças e adolescentes, resultados estes que são ressaltados pela pesquisa de (Brandão E, et al., 2017).

Souza HP, et al. (2020) em sua pesquisa identificou as áreas críticas relacionadas com as doenças parasitarias, entre elas esquistossomose, malária, dengue, doença de Chagas, entre outras. Seus dados mostraram que $40,5 \%$ dos municípios brasileiros apresentam alta criticidade, para a DC as regiões de maior relevância são o norte e nordeste devido a proximidade com áreas rurais e a grande quantidade de moradias impróprias que atraem o vetor.

Por mais que o Brasil tenha sido laureado em 2006 por ter realizado um controle ef etivo do vetor Triatoma infestans, os meios de infecção vão além da via vetorial e a correta identificação dos vetores da DC é extremamente necessário visto que a transmissão vetorial é a via clássica de transmissão, para tal identificação Gurgel Gonçalves R, et al. (2021) elaboraram o Triatodex um aplicativo que irá auxiliar futuramente na contenção da expansão vetorial, este aplicativo se mostra uma importante ferramenta já que outros estudos como o de Anderson AE, et al. (2018) mostram a presença de vetores pelo país, principalmente na região nordeste que apresenta uma grande variedade de espécies de triatomíneos.

Conforme elucidado na pesquisa de JUNIOR NC, et al. (2018), o Brasil também tem como desafio para as próximas décadas a implementação de um sistema de testagens em imigrantes de países endêmicos, já que os profissionais do Sistema Único de Saúde (SUS) desconhecem a clínica da doença e a ep idemiologia da doença em países vizinhos.

Alkmim-Oliveira SM, et al. (2014) realizaram um estudo epidemiológico em uma área endêmica brasileira para doença de Chagas e identificaram 76 chagásicos crônicos. Nesta pesquisa foi realizada a reação em cadeia da polimerase com primer específico único de baixa restringência (LSSP-PCR) que mostrou alta heterogeneidade entre as populações, no entanto, foram detectadas altas semelhanças $(80-100 \%)$ entre as cepas estudadas de pacientes de uma mesma família.

Alkmim-Oliveira SM, et al. (2014) expõem que a determinação das semelhanças genéticas entre populações de Trypanosoma cruzi isoladas de diferentes hospedeiros e vetores é muito importante para esclarecer a epidemiologia da doença de Chagas, já que infecções endêmicas tendem a ter sequências genéticas parecidas. A análise de PCR permite identificar a espécie e sua unidade de identificação. Outros estudos mais recentes como o de Vergara C, et al. (2019) mostram que a técnica de PCR realmente é mais precisa e específica, já que a partir desta técnica os pesquisadores conseguiram diagnosticar pacientes que haviam sido tratados com nifurtimox.

A partir do conhecimento da espécie e unidade exata de T.cruzi, se torna mais fácil o tratamento e a realização de medidas profiláticas. Assim nas próximas décadas, trabalhos que envolvam análises moleculares em sua amostragem podem traçar melhor o perfil epidemiológico da Doença de Chagas, mostrando se o parasito em questão já é proveniente de uma determinada região, ou se trata de infecções emergentes provenientes de outras regiões.

Existe a necessidade da reformulação na metodologia de diagnósticos, visto que Sáez-Alquezar $\mathrm{A}$, et al. (2021) e Ferreira-Silva MM, et al. (2020) estudaram a performance dos kits de diagnóstico para Doença de 
Chagas, os dados se mostraram satisfatórios, mas ainda há a presença de kits que não se apresentaram específicos para diagnóstico, apresentando dados contrário a outros kits. Brossas JY, et al. (2021) também estudou metodologia de diagnóstico para DC através da técnica de Western blotting, os resultados mostraram boas perspectivas. Dado que diversas pesquisas analisam as metodologias de diagnóstico e apresentam resultados adversos se faz necessário repensar a maneira de estudar e diagnosticar para trabalhos epidemiológico.

O país atualmente se encontra em situação de carência no sistema de testagens, dificultando assim a localização de endemias emergentes e sua contenção. Atualmente as prioridades políticas não estão voltadas para a contenção da distribuição de parasitos, tal situação não traz perspectivas positivas para o controle da doença, assim se faz necessário o apoio da vigilância epidemiológica com a criação de um sistema de testagens Nacional para conter os avanços da doença, a partir de seu rastreamento (DIAS JCP, et al., 2016; COURA JR, et al., 2012; SILVEIRA AC, et al., 2011; ALVES MARTINS LP, et al.,2011).

Apesar do declínio geral da mortalidade pela DC no Brasil apresentado por diversos autores nesta revisão integrativa, ela continua sendo um importante problema de saúde pública e as medidas devem ser mais estratificadas para regiões Norte e Nordeste, devido a maior incidência da DC nestas regiões, onde outros vetores além do $T$. infestans têm papel fundamental e pela transmissão oral ser bastante prevalente nestas regiões (ANDERSON AE, et al., 2018; SILVEIRA AC, et al., 2011; MARTINS-MELO FR et al., 2012; OSTERMAYER AL, et al., 2011).

O Brasil apresenta ótimos profissionais no campo da parasitologia, portanto atitudes independentes de medidas políticas nos próximos anos, como congressos e treinamentos para melhorar o olhar clínico de microscopista que já fazem triagem de outras doenças, como a malária no norte do país podem facilitar e melhorar a vigilância epidemiológica e a auxiliar na contenção da doença (MONTEIRO WM, et al., 2020). Mundialmente há diversas pesquisas voltadas para a descoberta de terapias mais eficazes contra 0 Trypanossoma cruzi, possivelmente nas próximas décadas possam aparecer novas formas terapêuticas que auxiliem no tratamento da DC (SILVEIRA AC, et al., 2011; OSTERMAYER AL, et al., 2011;).

É importante salientar que a análise de muitos autores foi feita a partir dos dados do SINAN e dados de mortalidade dispostos pelo Ministério da Saúde. As estatísticas da Doença de Chagas poder ser muito adversa, uma vez que a sua comorbidade pode ser facilmente confundida com outras doenças cardíacas e os diagnósticos podem não ter sido precisos, portanto, desde a sua descoberta, a doença de Chagas deve ser bem mais prevalente na sociedade do que mostrado na literatura (MARTINS-MELO FR, et al., 2012; MOTA JC, et al., 2014; ALENCAR ME et al., 2020; SANTOS EF, et al., 2020)

\section{CONSIDERAÇÕES FINAIS}

A vigilância epidemiológica se mostra um importante aliado para doenças que ainda não apresentam tratamento adequado. Além disso, ainda que existisse um tratamento eficaze que chegasse a todos pacientes com DC, a vigilância epidemiológica ainda seria essencial para DC, porque trata-se de uma zoonose, e ainda uma doença sempre emergente pelo fato de também circular entre os animais. Desse modo, esta revisão integrativa expõe a necessidade de mais pesquisas epidemiológicas, com metodologias de diagnóstico mais precisas. Conforme revisado, a DC se manifesta por todo o país de maneira heterogênea, por consequência trabalhos com amostragem regionais não mostram o real perfil epidemiológico da DC pelo país. Nas próximas décadas a vigilância epidemiológica ainda será a principal ferramenta para o controle da DC.

\section{REFERÊNCIAS}

1. ACOSTA RODRÍGUEZ EV, et al. Understanding CD8+ T Cell Immunity to Trypanosoma cruzi and How to Improve It. Trends in Parasitology, 2019;35(11): 899-917.

2. ALENCAR ME, et al. Epidemiology of acute Chagas Diseases in Brazil from 2007 to 2018. Research, society and development,2020;9:10.

3. ALKMIM-OLIVEIRA SM, et al. High similarity of Trypanosoma cruzi kDNA genetic profles detected by LSSP-PCR within family groups in an endemic area of chagas disease in Brazil. Revista da Sociedade Brasileira de Medicina Tropical, 2014; 47(5):653-6. 
4. ALVES MARTINS LP, et al. Incidence of Trypanosoma cruzi transmission through breastfeeding during acute experimental Chagas disease. Brazilian Journal Infectious Disease Elsevier Editora Ltda, 2011;15(2): 116-118.

5. ANDERSON AE, et al. Patterns of vector species richness and species composition as drivers of Chagas disease occurrence in Brazil. International Journal of Environmental Health Research, 2018; 1369-1619.

6. BRANDÃO E, et al. Neglected tropical diseases in Brazilian children and adolescents: data analysis from 2009 to 2013.Infectious Diseases of Poverty, 2017; 6: 154.

7. BROSSAS JY, et al. Evaluation of the Chagas Western Blot IgG Assay for the Diagnosis of Chagas. Disease Pathogens, 2021;10: 1455.

8. CORREIA JR, et al. Doença de Chagas: aspectos clínicos, epidemiológicos e fisiopatológicos. Revista Eletrônica Acervo Saúde, 2021:13(3):1-7.

9. COURA JR, BORGES-PEREIRA J. Chagas disease: What is known and what should be improved: a systemic review. Revista da Sociedade Brasileira de Medicina Tropical, 2012;45(3):286-96.

10. DIAS JCP, et al. Aspectos Gerais da Epidemiologia da Doença de Chagas com Especial Atenção ao Brasil. Revista do Sistema Unico Saude do Brasil, 2016;25: 7-86.

11. DIAS JCP, et al. Os primórdios do controle da doença de Chagas (em homenagem a Emmanuel Dias, pioneiro do controle, no centenário de seu nascimento). Revista da Sociedade Brasileira de Medicina Tropical, 2011;44(suppl 2): 12-8.

12. FERREIRA-SILVA MM, et al. 2020 Chagas disease: Performance analysis of immunodiagnostic tests antiTrypanosoma cruzi in blood donors with inconclusive screening results. hematology transfusion and cell therapy, 2021; 4 3(4): 410-416.

13. FONSECA BP, et al. Neglected tropical diseases in Brazil: lack of correlation between disease burden, research funding and output. Tropical Medicine and International Health, 2020;25(2):1373-1384.

14. GONÇALVES W, et al. Caracterização epidemiológica das mortes por doença de Chagas ocorridas no Brasil no período de 2010 a 2019. Research, Society and Development, 2021;10(10): e592101019096.

15. GURGEL-GONCALVES R, et al. TRIATODEX, an electronic identification key to the Triatominae (Hemiptera: Reduviidae), vectors of Chagas disease: Development, description, and performance. PLoS ONE, 2021; 16(4): e0248628.

16. HASHIMOTO K e YOSHIOKA K. Review: Surveillance of Chagas Disease. Advances in Parasitology, Elsevier;2012; 79:375-428.

17. JUNIOR NC, et al. Migração boliviana e doença de chagas: Limites na atuação do sistema único de saúde Brasileiro (SUS). Interface Communication Health Education, 2018;22(64):87-96.

18. LIDANI KC, et al. Chagas Disease:From Discovery to a Worldwide Health problem. Frontiers in public health, 2019; 7:166.

19. LIMA NT, BOTELHO A. Malária como doença e perspectiva cultural nas viagens de Carlos Chagas e Mário de Andrade à Amazônia. Historia Ciencias, Saude - Manguinhos, 2013;20(3):745-63.

20. MARTINS-MELO FR, et al. Mortality due to Chagas disease in Brazil from 1979 to 2009: trends and regional differences. Journal of Infection in Developing Countries, 2012;6(11):817-824.

21. MARTINS-MELO FR, et al. Multiple causes of death related to Chagas' disease in Brazil, 1999 to 2007 . Revista da Sociedade Brasileira de Medicina Tropical, 2012;45(5):591-6.

22. MARTINS-MELO FR, et al. The burden of Neglected Tropical Diseases in Brazil, 1990-2016: A subnational analysis from the Global Burden of Disease Study 2016. PLoS Neglected Tropical Disease, 2018;12(6): e0006559.

23. MONTEIRO WM, et al. Driving forces for strengthening the surveillance of chagas disease in the brazilian amazon by "training the eyes" of malaria microscopists. Revista da Sociedade Brasileira de Medicina Tropical, 2020; 53: 10-2.

24. MOTA JC, et al. Estimativa de taxa de mortalidade e taxa de incidência de sequelas cardíacas e digestiva s por doença de Chagas no Brasil, 2008. Epidemiol e Serviços Saúde, 2014;23(4): 711-20.

25. OSTERMAYER AL, et al. The national Survey of seroprevalence for evaluation of the control of Chagas disease in Brazil (2001-2008). Revista da Sociedade Brasileira de Medicina Tropical, 2011;44(SUPPL.2):108-21.

26. PESSONI LL, et al. Prevalence and trends in transfusion-transmissible infections among blood donors in Brazil from 2010 to 2016 . Hematology, transfusion and cell therapy, 2019;41(4):310-315.

27. PINHEIRO E, et al. Chagas disease: review of needs, neglect, and obstacles to treatment access in Latin America. Revista da Sociedade Brasileira de Medicina Tropical, 2017,50(3):296-300.

28. PRATA A, et al. Os primórdios da doença. Revista da Sociedade Brasileira de Medicina Tropical, 2011; 44(SUPPL. 2): $6-11$.

29. SÁEZ-ALQUEZAR A, et al. Geographical origin of chronic Chagas disease patients in Brazil impacts the performance of commercial tests for anti-T. cruzi lgG. Memórias do Instituto Oswaldo Cruz, 2021; 116:e210032.

30. SANGENIS LHC, et al. Transmissão da doença de Chagas por consumo de carne de caça: Revisão sistemática. Revista Brasileira de Epidemiologia, 2016;19(4):803-11.

31. SANTOS E, FALCÃO LM. Chagas cardiomyopathy and heart failure: From epidemiology to treatment. Revista Portuguesa de Cardiologia, 2020;39(5):279-289.

32. SANTOS EF, et al. Acute chagas disease in brazil from 2001 to 2018: A nationwide spatiotemporal analysis. PLoS Neglected Tropical Disease, 2020;14(8): 1-16.

33. SILVEIRA AC, et al. O inquérito de soroprevalência da infecção chagásica humana (1975-1980). Revista da Sociedade Brasileira de Medicina Tropical, 2011;44(SUPPL. 2): 33-9.

34. SILVEIRA AC. New challenges and the future of control. Revista da Sociedade Brasileira de Medicina Tropical, 2011; 44(SUPPL. 2): 122-4.

35. SIMÕES TC, et al. Chagas disease mortality in Brazil: A Bayesian analysis of age-period-cohort effects and forecasts for two decades. PLoS Neglected Tropical Disease, 2018;12(9): e0006798.

36. SOUZA HP, et al. Doenças infecciosas e parasitárias no Brasil de 2010 a 2017: aspectos para vigilância em saúde. Pan American Journal of Public Health, 2020; 44: e10.

37. VERGARA C, et al. Detection of Trypanosoma cruzi by PCR in adults with chronic Chagas disease treated with nifurtimox. PLOS ONE, 2019;14(8): e0221100.

38. XAVIER IGG, et al. Revalence of metabolic syndrome and associated factors among patients with chronic $\mathrm{Chagas}$ disease. PLoS ONE, 2021; 16(4): e0249116. 